\title{
Bringing Network Governance Into the Field of Violence and Integrity in Sports
}

\author{
Dr. Vidar Stevens \\ Mulier Institute \\ Herculesplein 269, 3584 AA Utrecht, The Netherlands \\ E-mail: v.stevens@mulierinstituut.nl
}

Dr. Tine Vertommen

Thomas More University of Applied Sciences, Molenstraat 8, 2018 Antwerpen, Belgium; Social Epidemiology and Health Policy, University of Antwerp, Belgium

E-mail: tine.vertommen@thomasmore.be

Received: March 30, 2020 Accepted: April 24, 2020 Online published: April 29, 2020

doi:10.5296/jpag.v10i2.16778～URL: https://doi.org/10.5296/jpag.v10i2.16778

\begin{abstract}
To date, the knowledge base on the topic of violence and integrity in sports is limited, the scientific community is relatively small, and the research field is in its infancy. The few researchers have predominantly been working in silos, and, consequently, initial studies have examined this issue with a singular discipline approach. Violence in sport is a multifaceted issue that has physical, psychological, social and organizational consequences. The fragmentation of the research efforts in this area thus far has limited the possibility of formulating a clear, collaborative and international agenda for future research. In this article, we aim to build on previous research, but also borrow insights from public administration, to pave the way for new studies that look from a governance perspective at policy strategies for the prevention of interpersonal violence against young athletes in sports. Particularly, we aim, in line with the Dutch policy development, to discuss the value of local networks, and its challenges, as vehicles of collaboration and prevention.
\end{abstract}

Keywords: networks, governance, interpersonal violence, sports, integrity 


\section{Introduction: Networks as Vehicles for Policy-Making and Implementation}

Due to the public disclosure of some high-profile cases of child sexual abuse in sport, the protection of athletes of all ages and the prevention of violence and other integrity violations in sport is now a topical issue. The issue of interpersonal violence is well-documented in international literature outside sport. The World Report on Violence and Health defines interpersonal violence as, "the intentional use of physical force or power, threatened or actual, against oneself, another person, or against a group or community, that either results in or has a high likelihood of resulting in injury, death, psychological harm, maldevelopment, or deprivation." (Krug, Dahlberg, Mercy, Zwi, \& Lozano, 2002). Interpersonal violence can be committed by partners or family members, as well as acquaintances and strangers in the community.

Prevalence studies in the Netherlands estimate that $37 \%$ of athletes experience psychological violence, $12 \%$ sexual violence and $10 \%$ physical violence in sport before the age of 18 (Vertommen et al., 2016). There is limited data on the prevalence of the violence against adult athletes, but the anecdotal information available suggests there is a vulnerability of athletes of any age. There is also a recognition that some athletes, irrespective of age, are at a higher risk for experiencing violence based on gender, ethnic background, disability and sexual orientation. Extensive media coverage and lawsuits have created a sense of urgency around the issue of athlete protection and ethics management. They are now high on the agenda of national sport authorities and international sport organizations worldwide.

Violence in sport can be regarded as a wicked problem, as it involves many stakeholders with different interests and responsibilities as well as a diversity of emotions ranging from anger to fear and anxiety (Stevens, 2019). The complexity of this problem necessitates an all-comprehensive, and coordinated, policy approach in order to get a hold on the wicked problem, and to ensure that both in stages of policy-making and -implementation stakeholders collaborate to ensure safe sport environments for children and young adults. In the Netherlands, we currently observe with the new policy strategy of the 'Local Sport Agreements', that governments both at the national and local level encourage sport organizations, health organizations, schools, the police, and potentially other stakeholders, to set up local alliances and networks to prioritize, inter alia, the avoidance sexual child abuse in sports. This focus on network governance as policy strategy is an interesting development as both within individual countries and at the international level, public organizations are looking for appropriate new policy responses to prevent interpersonal violence against young athletes in sports.

To date, the knowledge base on the topic of violence and integrity in sports is limited, the scientific community is relatively small, and the research field is in its infancy. The few researchers have predominantly been working in silos, and, consequently, initial studies have examined this issue with a singular discipline approach. Violence in sport is a multifaceted issue that has physical, psychological, social and organizational consequences. The fragmentation of the research efforts in this area thus far has limited the possibility of formulating a clear, collaborative and international agenda for future research. In this article, 
we aim to build on previous research, but also borrow insights from public administration, to pave the way for new studies that look from a governance perspective at policy strategies for the prevention of interpersonal violence (hereafter referred to as 'IV') against young athletes in sports. Particularly, we aim, in line with the Dutch policy development, to discuss the value of local networks, and its challenges, as vehicles of collaboration and prevention.

We continue as follows. First, we introduce a brief history on policy strategies in the prevention of IV against child athletes from an international, and Dutch perspective. Second, we present the case of the Netherlands, where the focus of the policy strategies in the new 'Local Sport Agreements' changed from a central, top-down, policy strategy, to a bottom-up, horizontally coordinated policy approach. Thirdly, we discuss different types of networks that can be set-up in order to coordinate a comprehensive policy strategy in the field of violence and integrity in sports. Lastly, we reflect on the challenges that emerge when working in networks on the prevention of interpersonal violence against child athletes in sport settings.

\section{A Brief Policy History on IV Against Child Athletes}

\subsection{The International Status Quo}

Probably because of the 'sport is good, fun and healthy' imperative, the world of sport has been very slow in recognising and acknowledging the dark side of sports (Brackenridge, 2001; Vertommen, 2017). While public disclosures of abuse in sport barely surfaced in the past decades, recently more and more professional and amateur athletes reveal their experiences with sexual, physical and psychological abuse by their coaches, entourage or peer athletes. Backed up by scientific evidence of the prevalence of IV in sport, sports authorities can no longer deny the excesses that take place.

In September 1990, the Convention on the Rights of the Child (CRC) entered into force. At the time of writing, all countries, except for the United States, have ratified the convention. The UN CRC clearly stipulated the need to protect the right to play (article 15) and the right to be kept safe from harm within any social setting (article 31). The declaration specifically states that stakeholders shall take all appropriate legislative, administrative, social and educational measures to protect children from all forms of violence (article 19). Although it succeeded in putting children's rights on the national agendas, the significance of the CRC is mainly symbolic as it lacks a mandate to sanction violations of its content.

To date, the most ambitious and comprehensive international legal instrument for the protection of children is the Council of Europe Convention on the Protection of Children against Sexual Exploitation and Sexual Abuse, also known as 'the Lanzarote Convention' (Council of Europe, 2007). The convention criminalises all kinds of sexual offences against children and incites all 47 Council of Europe parties to adopt specific legislation and to take preventive measures to protect children. Its monitoring body, the Lanzarote Committee, regularly evaluates whether the member states are effectively implementing the convention.

In addition, in 2011 the European Parliament released a directive on combating the sexual abuse and exploitation of children and child pornography (European Parliament, 2011). The directive aims to harmonise criminal offences related to child sexual abuse throughout the 
European Union and lays down minimum sanctions. Furthermore, it aims to prevent convicted sex offenders from exercising professional activities involving regular contact with children.

The first document to extensively address sexual violence against (child) athletes is the European Council's resolution on the prevention of sexual harassment and abuse of women, young people and children in sport (Council of Europe, 2000). The resolution stipulates that European Ministers responsible for Sport should commission research and collect data at the national level to ascertain the scale of the problem and prepare a national policy that makes a clear statement about the absolute need to safeguard and promote the welfare of children, young people and women in sport. The resolution asks for a clear condemnation of all forms of sexual violence against these athlete groups and urges member states to encourage national sport organisations to take preventive measures.

In 2004, Panathlon International, a non-governmental organisation that deals with ethical issues in sport, drafted the Panathlon Declaration on Ethics in Youth Sport (Panathlon International, 2004), which involves a charter that sports organisations can sign to show their commitment to upholding ethical values in youth sport. The declaration, which has been ratified by hundreds of national and international sports organisations, emphasises equity, fair play and ethics but does not explicitly mention child maltreatment, child abuse or other transgressive behaviour. This omission is intentional and prompted by the authors' persuasion to highlight the positive values of sport and avoiding deter children and young people, their parents and sponsors from sport (Vanden Auweele, 2004).

In 2007, the most powerful of all international sport organisations, the International Olympic Committee (IOC), released a consensus statement on the topic of sexual harassment and abuse in sport (International Olympic Committee, 2007). This document defines the problems, identifies the risk factors and provides guidelines for prevention and a resolution with the aim to improve athlete health and welfare through the promotion of effective preventive policies and awareness raising activities among the athletes' entourage. Following this statement, the IOC released a website containing educational modules to raise the awareness in athletes, coaches and sport federation members about the issue. In 2016, the IOC renewed its engagement with the topic by releasing an update and elaboration of the Consensus to all types of 'non-accidental harm' against athletes, urging sport federations to take all necessary actions to protect and safeguard athletes in sport (Mountjoy et al., 2016).

At the European Union level, IV in sport first received political attention in 2014 during the Greek EU presidency, when the fight against gender-based violence in sport was one of the main topics in the debates (Council of the European Union, 2014). As a follow-up, in 2016, the European Commission's expert group on the protection of minors in sport published recommendations on the protection of young athletes in which key actions for member states, the European Commission and sport organisations/associations are formulated (European Commission Expert Group on Good Governance, 2016). Most recently, under the Finnish Presidency, the European Council Conclusions on Safeguarding Children in Sport (2019) emphasize not only the need for protective and reactive measures towards IV in sport, but 
prioritize proactive safeguarding action from a broader perspective of children's wellbeing in sport.

We note a significant increase in political attention to the topic of athlete welfare, protection and safeguarding. However, IV against athletes other than sexual violence has apparently largely escaped the policy-makers' attention. The available recommendations aimed at the protection of children in sport merely focus on preventive and protective measures. Few of the policies mentioned above suggest standardized data-collection initiatives to assess the magnitude of all types of IV in sport. Equally, they barely propose (investigations into) measures to prosecute, punish perpetrators of IV in sport and to provide services to support both victims and perpetrators.

While we can conclude that worldwide authorities no longer disregard the topic, we are still far removed from a widely adopted uniform, evidence-based prevention framework. The traditional autonomy of sport, with minimal governmental interference, has led to reluctance to child welfare reforms and progress being stalled, with substantial differences among and within countries becoming apparent with regard to the level of recognition of the problem and the willingness to develop and implement prevention policies. In the following section, we zoom in on the policy situation in the Netherlands.

\subsection{The Status Quo in the Netherlands}

After a high-profile case of sexual violence against three elite judo athletes in 1996, the Netherlands Olympic Committee*Netherlands Sports Confederation (NOC*NSF), the Dutch umbrella federation of organised sports, initiated a comprehensive prevention policy targeting sexual violence in Dutch sports. Since, the NOC*NSF has run a nationwide programme against sexual intimidation in sport, whose two main goals are to develop (1) a structure that assists sport federations in dealing with an incident of sexual intimidation and (2) a prevention programme to eliminate the permissive, bystander culture within sport (Schipper-van Veldhoven, Vertommen \& Vloet, 2014). One of the first steps was to draw up a code of conduct for all sport coaches (NOC*NSF, 1997). The code was developed in discussion with more than 100 representatives from various Dutch sport organisations. A key and unique element in that policy was the provision of a national telephone helpline for athletes, coaches and other parties (in) directly involved in incidents of sexual harassment and abuse. Forming the back office of the helpline, a national pool of professional counsellors assists victims, perpetrators and (club) board members when such incidents are disclosed

A decade into the policy, NOC*NSF included the sexual harassment policy into a wider 'Safe Sport Climate' programme, launched in 2011 with the collaboration of the Dutch Ministry of Health, Welfare and Sports. The focus of this programme was no longer only on sexual harassment and abuse, but also on other types of IV in sport. By 2013, all federations were obliged to include the code of conduct for coaches in their regulations, incorporating penalties for non-compliance and associated procedures. Over the years, a range of supportive tools were developed to help the sport federations to establish the necessary structures and committees to execute the preventive and repressive measures, including a criminal record check for volunteers working with young people. 
Quite recently, the Netherlands has launched a new 'governance approach', by focussing on setting up local alliance and asking stakeholders to draft 'Local Sport Agreements', to inter alia ensure the prevention of IV against child athletes in sport settings. This new policy strategy emerged after the topic of sexual child abuse in sports received renewed attention by Dutch media and politicians. The rise of political and media attention for this matter started on the $6^{\text {th }}$ of July, 2017 when former football player Renald Majoor shocked the Dutch sport's world with his public statement about the horrific sexual abuse he suffered from a young age by one of his coaches (Volkskrant, 2017a). Around the same time, also other sport players opened up about their sexual child abuse experiences by their former trainers and teammates (Volkskrant, 2017b).

To get a better overview of the severity of the problem, the Dutch government installed a political commission to examine in-depth the issue of sexual child abuse within all areas of sports during the period 1970-2017. The conclusions of this commission were presented on the $12^{\text {th }}$ of December, 2017, and they were disturbing: 1 out of 8 children has during his or her sports' career experienced a form of unwanted sexual behavior by trainers or teammates, varying from bullying to assault and rape (De Vries et al., 2017). In consequence, the Dutch government, sports umbrella organizations and the Dutch Olympic Committee (NOC*NSF) have launched various prevention- and support programs to make local sport clubs more aware of sexual child abuse in their associations and to give them tools to protect the children who daily practice on their pitches, running courses or other sport facilities. In the next section, we elaborate on these new policy actions which follow from the 2019 National Sport Agreement.

\section{A Paradigm Change: Local Networks in the Netherlands on IV in Sports}

In 2019, the Ministry of Health, Welfare and Sport signed with national sport federations, NOC*NSF, and municipalities the National Sport Agreement. The National Sport Agreement is an overarching policy strategy that aims to create synergy in efforts of public (but also private) partners to create an, open, health, inclusive and sustainable sport infrastructure in the Netherlands. The National Sport Agreement consists of five broad themes on which a multitude of stakeholders the next years will focus. These five ${ }^{1}$ themes are: inclusiveness in sports, sustainable sport infrastructure, vital sport providers, sports for all ages, and positive sport culture. The last category, positive sport culture, inter alia focusses on IV against child athletes in sport settings. As such, the integrity and violence in sport settings, as well the demand for safe sport environments, got a dominant place in the current Dutch sport policy. To ensure, the local implementation of the National Sport Agreement, local municipalities are encouraged to agree on Local Sport Agreements.

\footnotetext{
${ }^{1}$ Although 'professional sport' will be included as a sixth theme from 2020 onwards.
} 


\section{MInstitute Macrothink $_{\text {Intion }}$}

Journal of Public Administration and Governance

ISSN 2161-7104 2020, Vol. 10, No. 2

Table 1. Priorities of local municipalities in Local Sport Agreements

\begin{tabular}{|l|c|}
\hline Broad theme (subtheme) & $\begin{array}{c}\text { \% } \\
\text { municipalities } \\
\text { (N=155) }\end{array}$ \\
\hline Inclusiveness in sports (every Dutch citizen must enjoy a positive life-long sport experience) & 92 \\
\hline Inclusiveness in sports (barriers to sport participation are taken away) & 85 \\
\hline Sports for all ages (more people conform to the exercise norms) & 79 \\
\hline Sports for all ages (motoric skills of people increase) & 85 \\
\hline $\begin{array}{l}\text { Sustainable sport infrastructure (sport accommodations are turned into multifunctional } \\
\text { facilities) }\end{array}$ & 61 \\
\hline Sustainable sport infrastructure (exploitation of sport facilities is strengthened) & 46 \\
\hline Sustainable sport infrastructure (all outside sport spaces are useable for recreation and sports) & 77 \\
\hline Sustainable sport infrastructure (all sport accommodations are sustainable) & 57 \\
\hline Vital sport providers (sport providers focus on a sustainable sport future) & 77 \\
\hline Vital sport providers (financial strength of sport providers is strengthened) & 62 \\
\hline Vital sport providers (providers increase the provision of sport) & 68 \\
\hline Vital sport providers (the societal purpose of sport is strengthened) & 63 \\
\hline Positive sport culture (establish a positive and safe sport climate) & 74 \\
\hline Positive sport culture (prevention of abuse in sport) & 50 \\
\hline
\end{tabular}

Local Sport Agreements are intention documents between local municipalities, local sport organizations, health organizations, schools, the police, and potentially other stakeholders, to set up local alliances and networks to synergize their sport efforts. The Local Sport Agreements have to follow the themes set out in the National Sport Agreement, but local stakeholders are free to choose whether they want to establish a Local Sport Agreement, and if they want to, on which of the themes they will focus the next four years. Local municipalities can receive money from the national level to organize the policy-making process for a Local Sport Agreement, and municipalities can even use a sport-chairman (in Dutch: sportformateur) to manage the decision-making process and foster collaboration between the multiplicity of stakeholders.

So far (last update has been Dec. 2, 2019), 339 municipalities have shown interest or are busy with initiating a Local Sport Agreement. Of these 339 municipalities, 155 municipalities are actually in the process of deciding on the priorities (and 44 of these municipalities have already drawn up their Local Sport Agreement). Looking at the intention documents of the first 155 municipalities (see table 1), we can notice that not all local (sport)stakeholders prioritize the topic of positive sport culture and, more in particular, not many focus in their sport agreements on the prevention of abuse in sport settings. Looking at the municipalities that incorporate the goal of prevention of abuse in sport setting in their Local Sport Agreements, the main focus is on increasing the pedagogic skills of trainers, and design policies that aim to reduce the amount of sexual intimidation among peers in sport settings. 
Table 2. Policy Strategies in Local Sport Agreements regarding IV

\begin{tabular}{|l|l|}
\hline \multicolumn{1}{|c|}{$\begin{array}{c}\text { Policy strategy in prevention of IV in sport settings } \\
\text { (multiple responses per Local Sport Agreement possible) }\end{array}$} & \multicolumn{1}{|c|}{$\begin{array}{c}\text { \% of the municipalities } \\
\text { (N=77) }\end{array}$} \\
\hline $\begin{array}{l}\text { Strategy 1: Improve the safe sport climate in local sport } \\
\text { clubs }\end{array}$ & 17 \\
\hline $\begin{array}{l}\text { Strategy 2: Draft rules and regulations concerning social } \\
\text { safety }\end{array}$ & 23 \\
\hline Strategy 3: Focus on parents and their behavior & 20 \\
\hline $\begin{array}{l}\text { Strategy 4: Increase the pedagogic skills of trainers and } \\
\text { coaches }\end{array}$ & 35 \\
\hline Strategy 5: Reduce the prevalence of sexual intimidation & 30 \\
\hline Different strategies & 13 \\
\hline
\end{tabular}

Within the National Sport Agreement, the topic of violence and integrity in sports is regarded as a wicked problem, as it involves many stakeholders with different interests and responsibilities as well as a diversity of emotions ranging from anger to fear and anxiety (Stevens, 2019). The complexity of this problem necessitates an all-comprehensive, and coordinated, policy approach in order to get a hold on the wicked problem, and to ensure that both in stages of policy-making and-implementation stakeholders collaborate to ensure safe sport environments for children and young adults. The Local Sport Agreements encourage the establishment of local alliances and networks to prioritize, inter alia, the prevention of interpersonal violence against young athletes in sports. It is too soon to evaluate the success and impact of the Local Sport Agreements, and thereby the local alliances, on the prevention of IV against athletes in sport settings.

From the network governance literature, however, we know that the success of a local alliance depends on different variables, like the coordination of the alliance, the motivation of stakeholders to participate (i.e. are they reluctant or not), the pre-history regarding collaboration between partners, resources, or power asymmetries (Stevens, 2018; Klijn \& Koppenjan, 2016). As such, the 'most suitable' structural design of a local alliance or network can differ for each local context and involved group of stakeholders. In the next section, we therefore elaborate on the different 'ideal-typical' network structures a local alliance can have, and what the benefits are of each of these structures. We, specifically, build on network governance literature. In this way, we aim to encourage local policy-makers in the Netherlands to also think about the structural set-up of the local alliances, and the effect these set-ups have, on dealing with the wicked issues of interpersonal violence against young athletes in sport contexts.

\section{Different Types of Networks to Prevent IV Against Child Athletes}

Network governance is a topic that has long been studied by scholars in public administration (Klijn \& Koppenjan, 2016; Provan \& Kenis, 2008; Stevens \& Verhoest, 2016). We define local alliances or networks as sets of autonomous yet interdependent stakeholders (e.g. sport clubs) that have developed enduring relationships in governing specific public problems or policy programs. The complexity of these networks is implied in one of the most important 
books on networks: Hanf and Scharpf's Interorganizational Policy Making: Limits to Coordination and Central Control (1978). The main argument of Hanf and Scharpf is that although the stakeholders who deal with policy problems are interdependent to each other for resources, there usually are no fixed 'institutional' governance structures set up that deal with these interdependencies. Instead, stakeholders operate in a loosely structured web of interactions, with limited institutional rules, with the aim to tackle a problem or issue collaboratively.

It is good to highlight that our definition of what we understand as a local alliance or network, or in the Dutch case 'local alliance', focuses on what Kilduff and Tsai (2003) refer to as 'goal-directed', as opposed to 'serendipitous' networks. Although goal-directed networks occur less frequently, they have become extremely important as formal mechanisms for achieving collaborative outcomes (Klijn \& Koppenjan, 2016). Serendipitous interactions, of course, can occur within goal-directed networks, resulting in co-evolutionary trajectories that may prove advantageous or detrimental to network outcomes. However, unlike serendipitous networks, which develop opportunistically, goal-directed networks are set up with a specific purpose, either by those who participate in the network or through mandate, and evolve largely through conscious efforts to build coordination and collaboration. A local alliance can, for example, be established with the specific purpose to collaborate to reduce the amount of IV against child athletes at local sport clubs. Consistent with this logic, we view a goal-directed network as a 'variable', which can have different network structure configurations.

Various contingencies determine what form of network structure is most appropriate for a given policy situation. Some of these contingencies include: commitment of stakeholders, difference in views regarding the policy problem and solution, and the amount of resources each stakeholder possesses (Stevens, 2018; Koppenjan \& Klijn, 2004). Perhaps, the most important contingency is the need for control and control to ensure conformity and uniformity in a policy process. That is to say, within some policy situations strict coordination is required, whereas in other situations a more laissez-faire coordination approach is demanded (Provan \& Kenis, 2008).

We believe three ideal types of network structures (see table 3) can be distinguished: a central-, a cascade-, and a lateral governed form of network. These three forms of network structures differ in the amount of coordination that is exerted on individual stakeholders in the policy-making and -implementation process by a central coordinator. We interpret a central governed network structure as the 'most' controlling way of organizing the interactions of a policy process and the 'lateral' as the most 'laissez faire' in terms of coordination. The cascade governed network structure is an intermediary form between the two 'extreme' ideal types. The three network structures differ among three dimensions: a relational, policy-making and implementation dimension. We elaborate on each of these dimensions below. 
Table 3. Three ideal types of network structures for local IV alliances

\begin{tabular}{|c|c|c|c|}
\hline $\begin{array}{l}\text { TYPE OF } \\
\text { NETWORK }\end{array}$ & $\frac{\text { CENTRAL GOVERNED }}{\underline{\text { NETWORK }}}$ & $\frac{\text { CASCADE GOVERNED }}{\underline{\text { NETWORK }}}$ & $\frac{\text { LATERAL GOVERNED }}{\underline{\text { NETWORK }}}$ \\
\hline $\begin{array}{l}\text { RELATIONAL } \\
\text { DIMENSION }\end{array}$ & $\begin{array}{l}\text { One (or more) assigned } \\
\text { central stakeholder(s) } \\
\text { 'hierarchically'steer(s) the } \\
\text { governance process and } \\
\text { determines what tasks and } \\
\text { roles other actors have to } \\
\text { perform. The way of } \\
\text { interacting is very } \\
\text { command-driven to ensure } \\
\text { conformity. }\end{array}$ & $\begin{array}{l}\text { One (or more) central } \\
\text { stakeholder(s) give guidance to the } \\
\text { network process, but there is } \\
\text { 'delegated'decision-making } \\
\text { freedom for subsets of stakeholders } \\
\text { to determine their own contributions } \\
\text { to the governance process. The way } \\
\text { of interacting is very } \\
\text { cascade-driven. }\end{array}$ & $\begin{array}{l}\text { The morphology of the } \\
\text { network follows the principle } \\
\text { of self-governance. This } \\
\text { means that individual } \\
\text { stakeholders govern their } \\
\text { own policy efforts and decide } \\
\text { themselves with whom they } \\
\text { collaborate, what role they } \\
\text { take on, and what their } \\
\text { responsibilities are in the } \\
\text { network process. }\end{array}$ \\
\hline $\begin{array}{l}\text { POLICY-MAKING } \\
\text { DIMENSION }\end{array}$ & $\begin{array}{l}\text { A 'fixed'policy strategy } \\
\text { and targets are defined on } \\
\text { the basis of how the central } \\
\text { stakeholder(s) perceive(s) } \\
\text { the nature of the policy } \\
\text { problem and what } \\
\text { necessary solutions are. }\end{array}$ & $\begin{array}{l}\text { An overarching policy strategy is } \\
\text { defined to provide consistency in the } \\
\text { focus of the different network } \\
\text { activities. Within the parameters of } \\
\text { the overarching policy strategy, } \\
\text { subgroups of stakeholders can } \\
\text { define their own policy actions to } \\
\text { distinguish their policy } \\
\text { contributions from other policy } \\
\text { activities. }\end{array}$ & $\begin{array}{l}\text { Individual stakeholders } \\
\text { independently develop their } \\
\text { policy strategies. The } \\
\text { 'overall'policy strategy is, } \\
\text { thus, the total sum of the } \\
\text { individual policy efforts - } \\
\text { this, can cause that there are } \\
\text { inconsistencies and } \\
\text { contradictions among the } \\
\text { individual policy } \\
\text { approaches. }\end{array}$ \\
\hline $\begin{array}{l}\text { IMPLEMENTATION } \\
\text { DIMENSION }\end{array}$ & $\begin{array}{l}\text { The 'central stakeholder' is } \\
\text { exerting strict control over } \\
\text { the implementation } \\
\text { activities of the other } \\
\text { stakeholders by setting } \\
\text { clear protocols to ensure } \\
\text { that the policy strategy is } \\
\text { implemented in a manner } \\
\text { that reinforces the } \\
\text { objectives set by the central } \\
\text { stakeholder. }\end{array}$ & $\begin{array}{l}\text { There is a nested implementation } \\
\text { strategy, which means, that there are } \\
\text { general protocols and guidelines for } \\
\text { implementing policy, but within } \\
\text { subgroups, stakeholders can decide } \\
\text { together what the best policy mix is } \\
\text { to implement the policy objectives in } \\
\text { their particular policy context. }\end{array}$ & $\begin{array}{l}\text { Individual stakeholders can } \\
\text { decide for themselves what } \\
\text { potential policy strategies } \\
\text { they implement without any } \\
\text { pressure or force from } \\
\text { network peers. }\end{array}$ \\
\hline
\end{tabular}

The relational dimension considers the 'power distance' between stakeholders (Agranoff, 2006). In the central governed network structure, the coordinator unilaterally supervises the policy process, defines the tasks and roles of other stakeholders involved, monitors whether involved stakeholders keep themselves to agreed policy actions and tasks, and, if necessary, punishes transgressions. In the two other models, individual stakeholders have more decision-making rights and autonomy. That is to say, the cascade- and lateral governed network structures recognize that policy processes must calibrate the different ways in which stakeholders look at a policy problem, and therefore more 'discretionary room' for other 
stakeholders is preferred.

The models also differ in terms of policy-making. To reduce what can be understood as the 'cacophony of voices' (Stevens, 2019), the central governed network structure prefers one clear policy theory, causal path, and sort of solutions for the policy problem. There is limited room in this model for other narratives about the policy problem. The 'fixed' policy strategy and targets are often defined on the basis of how the central stakeholder(s) perceive(s) the nature of the policy problem and what necessary solutions are. However, in a network setting, a one-sided policy story may be seen as illegitimate or even impossible as it ignores the views, alternatives and approaches of groups or stakeholders that are involved in the policy setting. To this end, the cascade model and lateral model allow for multiple stories and policy targets in the network structure. The lateral model is the most extreme model, as it assumes that individual stakeholders independently develop their policy views, strategies, and policy plans. In the lateral model, the 'overall' policy strategy is, thus, the total sum of the individual policy actions. The danger of the lateral approach, however, is that there are inconsistencies and contradictions among the different policy approaches of the stakeholders, which can easily lead, in the implementation stage, to conflict, ineffective policy responses, or even non-collaboration between involved network peers.

In terms of policy implementation, the coordinator will, in the central governed network model, try to tightly control the implementation process and look for uniformity and cohesiveness in the mixture of policy strategies. 'Implementation control', as such, will not only be about exerting control over the policy activities of the other stakeholders in the local alliance, but also about ensuring that the mix of policy strategies is orchestrated in a manner that reinforces the strict objectives of the policy process. In the cascade governed network model, there is a nested implementation structure which means that there are general protocols and guidelines in place for implementation of policy objectives, but subgroups of stakeholders can decide what the best policy mix of strategies given a particular policy setting. In the lateral model, implementation practices are much more fluid, as individual stakeholders decide independently how they try to reach policy goals. In this sense, there is no implementation control exerted by a central coordinator over other stakeholders in the lateral governed network model.

Besides our three ideal-typical network structures, stakeholders can also opt for a fourth network structure option, which is the establishment of what Provan and Kenis (2008) call an externally governed network coordinated by a unique network administrative organization (NAO). This means that the stakeholders in the policy-making and implementation process do not choose to have one coordinator among their midst but decide to choose a third member party from outside the network setting to coordinate and structure the network set-up.

This can, for example, be an expert that already is familiar with the target policy goal and the management of collaborations (e.g. the sportformateurs that are suggested by the Local Sport Agreements in the Dutch case context). One of the reasons to choose for such a network setup could be that it is preferred that the responsibility for solving a policy problem, like reducing the amount of IV against child athletes at sport clubs, is put completely on the 
shoulders of an independent expert party that has no ties or interdependencies with any of the other involved stakeholder. Especially, in the case of mismanagement by one of the involved stakeholders this solution might be preferred. However, we expect that stakeholders will seldom choose for this network structure, as active involvement of stakeholders in a network setting stimulates the sustainability or survival of a network process.

\section{Final Reflections About Networks as Vehicles to Reduce IV Against Youth Athletes}

The attempt of local governments in the Netherlands to set-up local alliances can be considered an admirable effort, especially in relation to the topic of IV against child athletes in sport settings. As we have seen in this article, there are different network structures that can be chosen to support local alliances. Nevertheless, government officials have to consider that three important factors can hinder the longevity of a network process: the voluntary nature of sport clubs, the pressure on sport clubs to contribute to society in different ways, and the secrecy surrounding the topic of IV against child athletes. In a range of countries, including the Netherlands, voluntary sports clubs are the main provider of sport activities (Breuer et al., 2015; Waardenburg \& Van Bottenburg, 2013). This voluntary structure developed bottom up during the late nineteenth century and the beginning of the twentieth century. Dutch citizens started to organize their sport activities in voluntary sports clubs, which remain the most prominent sport organizations to date. In 2013, $30 \%$ of Dutch citizens were members of a voluntary sports club (Tiessen-Raaphorst \& den Dool, 2015). However, the board members of these voluntary sport clubs are often parents that during the day have a full-time job. This makes it difficult for 'volunteers' to comply to the expectation of many government officials about board members to be fully involved in the prevention of IV against child athletes in local sport settings.

In recent years, however, local sports clubs have been asked or pressured to contribute to such diverse issues as counteracting the obesity epidemic, promoting the social integration of minorities (Agergaard, 2011), tackling homophobia (Elling, Knoppers, \& De Knop, 2003), encouraging good citizenship behavior among refugees (Spaaij, 2015), improving social cohesion in neighborhoods and activating the elderly. This relationship between sports clubs and local municipalities is hardly new or surprising. The perceived positive functions that local sport clubs can play in society have long been described (e.g. Coalter, 2007). Nevertheless, there is a limit to the organizational capacity of local sport clubs to be 'public problem solvers'.

Lastly, we have to highlight the issue of taboo surrounding the topic of IV against child athletes. Athlete integrity violations often occur in an intimate context between athlete and coach or peers, where parents, the club or other involved stakeholders at the local level are hardly aware of or are unable to detect or intervene. Often, intervening is only possible after disclosure. It is important that in the Dutch policy context, local alliances discuss these issues and come up with helpful solutions to ensure that their efforts to establish effective networks do not turn into sleeping networks that have no policy impact at all. Future research can also help to find out how local networks and alliances best cope with these governance-related dilemmas. 


\section{Acknowledgement}

This article is a collaboration between researchers of the International Research Network on Violence and Integrity in Sports.

\section{References}

Agergaard, S. (2011). Development and appropriation of an integration policy for sport: How Danish sports clubs have become arenas for ethnic integration. International Journal of Sport Policy and Politics, 3(1), 341-353. https://doi.org/10.1080/19406940.2011.596158

Agranoff, R. (2006). Inside collaborative networks: Ten lessons for public managers. Public Administration review, 66(1), 56-65. https://doi.org/10.1111/j.1540-6210.2006.00666.x

Brackenridge, C. H. (2001). Spoilsports: understanding and preventing sexual exploitation in sport. London, United Kingdom: Routledge. https://doi.org/10.4324/9780203478936

Breuer, C., Hoekman, R., Nagel, S., \& van der Werff, H. (2015). Sport clubs in Europe. New York, NY: Springer. https://doi.org/10.1007/978-3-319-17635-2

Coalter, F. (2007). A wider social role for sport: who's keeping the score? London, United Kingdom: Routledge.

Council of Europe. (2000). Resolution on the prevention of sexual harassment and abuse of women.

Council of Europe.(2007). Convention on the Protection of Children against Sexual Exploitation and Sexual abuse. Retrieved from: https://www.coe.int/en/web/conventions/full-list/-/conventions/treaty/201.

Council of the European Union. (2014). Council Conclusions of 21 May 2014 on Gender Equality in Sport. Retrieved from: https://eur-lex.europa.eu/legal-content/EN/TXT/?uri=CELEX\%3A52014XG0614\%2809\%29

De Vries, K., Ross-Van Dorp, C., \& Myjer, E. (2016). Rapport van de Onderzoekscommissie Seksuele Intimidatie en Misbruik in de Sport. Nieuwegein, The Netherlands: Arko Sports Media.

Elling, A., Knoppers, A., \& De Knop, P. (2003). Gay/lesbian sport clubs and events: Places of homo-social bonding and/or cultural resistance? International Review for the Sociology of Sport, 38(1), 441-456. https://doi.org/10.1177/1012690203384005

European Commission Expert Group on Good Governance. (2016). Recommendations on the protection of young athletes and safeguarding children's rights in sport. Retrieved from: https://ec.europa.eu/transparency/regexpert/index.cfm?do=groupDetail.groupDetailDoc\&id= $25000 \&$ no $=1$.

European Parliament. (2011). Directive 2011/92/EU of the European Parliament and of the Council of 13 December 2011 on combating the sexual abuse and sexual exploitation of children and child pornography, replacing Council Framework Decision 2004/68/JHA. 
Hanf, K., \& Scharpf, F. W. (1978). Interorganizational Policy Making: Limits to coordination and central control. Thousand Oaks, CA.: Sage Publications.

International Olympic Committee. (2007). Consensus Statement on Sexual Harassment and Abuse in Sport. Lausanne, Switzerland: IOC press.

Kilduff, M., \& Tsai, W. (2003). Social networks and organizations. Thousand Oaks, CA: Sage Publications. https://doi.org/10.4135/9781849209915

Klijn, E. H., \& Koppenjan, J. F. M. (2016). Governance networks in the public sector. London, United Kingdom: Routledge.

Krug, E. G., Dahlberg, L. L., Mercy, J. A., Zwi, A. B., \& Lozano, R. (2002). World report on violence and health. Geneva: World Health Organization. https://doi.org/10.1016/S0140-6736(02)11133-0

Mountjoy, M., Brackenridge, C. H., Arrington, M., Blauwet, C., Carska-Sheppard, A., Fasting, K., \& Budgett, R. (2016). The IOC Consensus Statement: Harassment and abuse (non-accidental violence) in sport. British Journal of Sports Medicine, 50(1), 1019-1029. https://doi.org/10.1136/bjsports-2016-096121

NOC*NSF. (1997). Gedragsregels ter preventie van seksuele intimidatie in de sport. [Code of conduct for the prevention of sexual harassment in sport]. Arnhem, The Netherlands: NOC*NSF.

Panathlon International. (2004). Panathlon Declaration on Ethics in Youth Sport. Retrieved from. http://ethics.iit.edu/codes/PI\%202004.pdf

Provan, K. G., \& Kenis, P. (2008). Modes of network governance: Structure, Management, and Effectiveness. Journal of Public Administration Research and Theory, 18(2), 229-252. https://doi.org/10.1093/jopart/mum015

Schipper - van Veldhoven, N., Vertommen, T., \& Vloet, L. (2014). Sexual Intimidation in Sport: the Netherlands. This is a chapter. In M. Lang \& M. Hartill (Eds.), Safeguarding, Child Protection and Abuse in Sport: International Perspectives in Research, Policy and Practice. London, United Kingdom: Routledge.

Spaaij, R. (2015). Refugee youth, belonging and community sport. Leisure Studies, 34(3), 303-318. https://doi.org/10.1080/02614367.2014.893006

Stevens, V. (2018). Individual learning behaviour in collaborative networks. This is a chapter. In Dunlop, C., C. Radaelli, and P. Trein, Learning in Public Policy: Analysis, Modes and Outcomes. Basingstoke, United Kingdom: Palgrave-MacMillan.

Stevens, V. (2019). The Silent Topic of Sexual Child Abuse in Sports in the Academic Literature: How Network Governance, Public Branding, and Design-Oriented Public Administration Provide Avenues for Future Research. Journal of Public Administration and Governance, 9(3), 179-199. https://doi.org/10.5296/jpag.v9i3.15219

Stevens, V., \& Verhoest, K. (2016). A next step in collaborative policy innovation research: 
analysing interactions using Expontential Random Graph Modelling. The Innovation Journal: The Public Sector Innovation Journal, 21(2), 1-20.

Tiessen-Raaphorst, A., \& den Dool, R. (2015). Sportdeelname [Sports participation]. This is a chapter. In Tiessen-Raaphorst, A. (Ed.) Rapportage Sport 2014 [Sport Report 2014]. The Hague, The Netherlands: SCP.

Vanden, A. Y. (2004). Ethics in youth sport. Analysis and recommendations. Leuven, Belgium: Lannoo Campus.

Vertommen, T. (2017). Interpersonal Violence against Children in Sport. Dissertation for the degree of doctor in Medical Sciences. Antwerp: University of Antwerp.

Vertommen, T., Schipper-van Veldhoven, N., Wouters, K., Kampen, J. K., Brackenridge, C. H., Rhind, D. J., \& Van Den Eede, F. (2016). Interpersonal violence against children in sport in the Netherlands and Belgium. Child Abuse and Neglect, 51(1), 223-236. https://doi.org/10.1016/j.chiabu.2015.10.006

Volskrant (2017a). Seksueel Misbruik bij PSV en Vitesse Twee Oud Jeugdspelers treden naar Buiten. [Online] Available: https://www.volkskrant.nl/nieuws-achtergrond/seksueel-misbruik-bij-psv-en-vitesse-twee-ou d-jeugdspelers-treden-naar-buiten b2ef6057/.

Volskrant. (2017b). Hij hield mijn hand vast en bewoog hem heen en weer. [Online] Available: https://www.volkskrant.nl/sport/-hij-hield-mijn-hand-vast-en-bewoog-hem-heen-en-weer- b0 96dca5/.

Waardenburg, M., \& van Bottenburg, M. (2013). Sport policy in the Netherlands. International Journal of Sport Policy and Politics, 5(3), 465-475. https://doi.org/10.1080/19406940.2013.796566

Weber, M., de Bruin, A. P., \& Moget, P. (2006). The Dutch Program against Sexual Harassment in Sports 1996 - 2006. Arnhem, The Netherlands: NOC*NSF.

\section{Glossary}

IV: interpersonal violence

NOC*NSF: Dutch Olympic Association

\section{Copyright Disclaimer}

Copyright for this article is retained by the author(s), with first publication rights granted to the journal.

This is an open-access article distributed under the terms and conditions of the Creative Commons Attribution license (http://creativecommons.org/licenses/by/4.0/). 